\title{
Blue emission from polymer nanocomposites: preparation and application of multicolored luminescent materials
}

\author{
Takeshi Otsuka ${ }^{1,2}$ and Yoshiki Chujo ${ }^{2}$
}

Blue-emitting luminescent polymer nanocomposites were prepared from 1,3-diketone functionalized poly(methyl methacrylate) (PMMA) and zirconium oxide nanocrystals $\left(\mathrm{ZrO}_{2}-\mathrm{NCs}\right)$. Fourier transform infrared spectra suggested chemisorption of the 1,3-diketone by bidentate chelation of the diketonate anion to the $\mathrm{ZrO}_{2}-\mathrm{NC}$ surface. The $\mathrm{ZrO}_{2}-\mathrm{NCs}$ were well dispersed in the polymer matrix and crosslinked on the NC surfaces. The chemically crosslinked polymer nanocomposites had high photostability compared with the $\mathrm{PMMA} / \mathrm{ZrO}_{2}-\mathrm{NC}$ composites with 1,3-bis(4-methoxyphenyl)-1,3-propanedione. The stability of the luminescence from the polymer nanocomposites was enhanced because the 1,3-diketonate binding sites were fixed between inorganic NCs and polymer chains. The blue emission peaking at $448 \mathrm{~nm}$ can be tuned by the addition of 8-hydroxyquinolinecontaining copolymer/ZrO $2-\mathrm{NC}$ composite, which red-shifted the emission from blue to yellow and green as a function of the blend composition. This strategy, in which the ligand would be immobilized by an organic/inorganic sandwich structure, is suitable for obtaining not only well-stabilized luminescent nanocomposites but also nano-optoelectronics with controlled emission colors.

Polymer Journal (2011) 43, 352-357; doi:10.1038/pj.2010.144; published online 9 February 2011

Keywords: Iuminescence; nanocrystal; polymer nanocomposite; zirconium oxide; 1,3-diketone

\section{INTRODUCTION}

Organic-inorganic hybrid materials, or composite materials, are receiving attention for their diverse structures and many potential applications. ${ }^{1-3}$ Such nano-ordered heterogeneous conflations are widely utilized because of their intrinsically negligible light scattering and large specific surface area. Furthermore, utilizing inorganic nanoparticles as fine fillers for polymer offers new ways to produce novel and promising composite materials composed of organic polymers and highly dispersed inorganic nanocrystals (NCs). ${ }^{4,5}$

The adsorption of various dyes on inorganic NCs has been of great interest in the past. $^{6-9}$ Studies have so far concentrated on surface specificity and related photophysical reactions. Adsorption mechanisms have been analyzed using absorption, infrared, thermal desorption and luminescence spectroscopy and electron microscopy. In the case of wide band gap materials, the complexation of surface cations may give rise to the formation of chromophores acting as sensitizers. In our previous work, the 8-hydroxyquinoline-containing copolymer was shown to undergo a chelation reaction with colloidal zirconium oxide $\left(\mathrm{ZrO}_{2}\right)$, resulting in the formation of a bright yellow colored complex with inorganic NCs that was highly effective in stabilizing the luminescent nanocomposite. ${ }^{10}$
Herein, we report the luminescent polymer nanocomposite of 1,3diketone-containing copolymer with zirconium oxide nanocrystal $\left(\mathrm{ZrO}_{2}-\mathrm{NC}\right)$ by forming coordination complexes with $\mathrm{ZrO}_{2}-\mathrm{NCs}$. In the present study, the effects of $\mathrm{ZrO}_{2}$ chelation using methoxyfunctionalized dibenzoylmethane (MDBM) as a complexing agent were studied, and color tuning by the addition of 8-hydroxyquinolinecontaining copolymer $/ \mathrm{ZrO}_{2}-\mathrm{NC}$ composite was also explored in detail. $\mathrm{ZrO}_{2}$ is chemically stable, highly resistance to corrosion and electrically insulating. It has great mechanical strength and heat resistance and a high refractive index; all of these characteristics make this material suitable for a wide variety of applications. In particular, the $\mathrm{ZrO}_{2}-\mathrm{NC}$ aqueous sol, which contains tetragonal $\mathrm{ZrO}_{2}$-NCs $(3 \mathrm{~nm})$, is colorless and suitable for the preparation of organic polymer and $\mathrm{ZrO}_{2}$ nanocomposite materials. ${ }^{11-13}$

This strategy, in which luminescent sites are positioned on the $\mathrm{ZrO}_{2}-\mathrm{NC}$ surfaces and coordinated 1,3-diketone ligands are fixed between inorganic NCs and polymer chains, can produce highly stabilized luminescent nanocomposites. Another attractive feature of this system is the ease of color tuning by the addition of other ligands containing copolymer composites, which have potential applications in future nano-optoelectronics.

\footnotetext{
1Sumitomo Osaka Cement Co. LTD. 585, Toyotomi-cho, Funabashi-shi, Chiba, Japan and ²Department of Polymer Chemistry, Graduate School of Engineering, Kyoto University, Katsura, Nishikyo-ku, Kyoto, Japan

Correspondence: Professor Y Chujo, Department of Polymer Chemistry, Graduate School of Engineering, Kyoto University, Katsura, Nishikyo-ku, Kyoto 615-8510, Japan. E-mail: chujo@chujo.synchem.kyoto-u.ac.jp

Received 21 September 2010; revised 29 November 2010; accepted 1 December 2010; published online 9 February 2011
} 


\section{EXPERIMENTAL PROCEDURE}

Materials

Methyl methacrylate (MMA) monomer, 2-ethoxyethanol and toluene were purified by distillation under vacuum and stored under nitrogen. Azobisisobutyronitrile was recrystallized from ethanol at $35^{\circ} \mathrm{C}$. 1,3-Bis (4-methoxyphenyl)-1,3-propanedione was purchased from Tokyo Chemical Industry (Tokyo, Japan), and used without further purification. $\mathrm{ZrO}_{2}-\mathrm{NC}$ aqueous sol, which contained $10.0 \mathrm{wt} \% \mathrm{ZrO}_{2}$ with acetate anion $(\mathrm{pH}=1.7)$, was obtained from Sumitomo Osaka Cement (Tokyo, Japan).

\section{Measurements}

The ${ }^{1} \mathrm{H}$-nuclear magnetic resonance (NMR) and ${ }^{13} \mathrm{C}$-NMR spectra were recorded on a JEOL JNM-EX400 instrument (JEOL, Tokyo, Japan) at 400 and $100 \mathrm{MHz}$ at room temperature. $\mathrm{CDCl}_{3}$ with $0.05 \mathrm{vol} \%$ tetramemthylsilane was used in liquid NMR. The number-average-molecular weight $\left(M_{n}\right)$ and the molecular weight distribution (the ratio of weight-average-molecular weight to number-average molecular weight $\left.\left(M_{\mathrm{w}} / M_{\mathrm{n}}\right)\right)$ values of all of the polymers were estimated by size-exclusion chromatography with a TOSOH G3000HXI system (Tosoh, Tokyo, Japan) equipped with three consecutive polystyrene gel columns (TOSOH gels: $\alpha-4000, \alpha-3000$ and $\alpha-2500$ ) and an ultraviolet (UV) detector at $40{ }^{\circ} \mathrm{C}$. The system was operated at a flow rate of $1.0 \mathrm{ml} \mathrm{min}{ }^{-1}$, with tetrahydrofuran as an eluent. Polystyrene standards were used for calibration. Fourier transform infrared spectra were obtained using a SHIMADZU IR Prestage-21 (Shimadzu, Kyoto, Japan) using a $\mathrm{KBr}$ pellet as a standard. Scanning electron microscopy measurements were conducted using a JEOL JSM-5600B system. Ultraviolet-visible absorption spectra were measured with a SHIMADZU UV3600 spectrophotometer at room temperature. Photoluminescence spectra were recorded on a HORIBA JOBIN YVON FluoroMax-4 spectrofluorometer (Horiba, Kyoto, Japan) at room temperature. Ultraviolet irradiation was generated by a $400 \mathrm{~W}$ high-pressure mercury lamp with emission wavelengths longer than $310 \mathrm{~nm}$ through a Pyrex cooler (Sogo Laboratory Glass Works, Kyoto, Japan). The reaction was performed at room temperature. The size of the $\mathrm{ZrO}_{2}$-NC dispersed in the composite sol was determined by dynamic light scattering using an FPAR-1000 from Otsuka Electronics (Osaka, Japan).

\section{Procedures}

Synthesis of 2-propenoic acid, 2-methyl-,2-[4-[3-(4-methoxyphenyl)-1,3-dioxopropyl]-phenoxy]ethyl ester. 2-Propenoic acid, 2-methyl-,2-[4-[3-(4-methoxyphenyl)-1,3-dioxopropyl]phenoxy] ethyl ester (MDBM-MA) was prepared by a method reported previously ${ }^{14}$ with slight modifications. ${ }^{15}$ The NMR spectra of MDBM-MA have yet to be published. ${ }^{1} \mathrm{H}-\mathrm{NMR}\left(\mathrm{CDCl}_{3}, \delta\right.$, p.p.m.): 17.10 (s, 1H, enol OH), 7.98 (d, 4H, 2',6'-ArH, 2", 6' $6^{\prime \prime}-\mathrm{ArH}$ ), 6.97 (d, 4H 3',5'-ArH, $\left.3^{\prime \prime}, 5^{\prime \prime}-\mathrm{ArH}\right), 6.73$ (s, 1H, COCHCO), 6.15 ( $\mathrm{s}, 1 \mathrm{H}$, vinyl) 5.61 (s, $1 \mathrm{H}$, vinyl), 4.53 $\left(\mathrm{m}, 2 \mathrm{H}, \mathrm{Ar}-\mathrm{O}-\mathrm{CH}_{2}\right), 4.30\left(\mathrm{~m}, 2 \mathrm{H}, \mathrm{COO}-\mathrm{CH}_{2}\right), 3.89\left(\mathrm{~s}, 3 \mathrm{H}, \mathrm{O}-\mathrm{CH}_{3}\right), 1.96$ (s, $\left.3 \mathrm{H}, \mathrm{CH}_{3}\right) .{ }^{13} \mathrm{C}-\mathrm{NMR}\left(\mathrm{CDCl}_{3}\right.$, $\delta$, p.p.m.): $184.7,184.4,167.3,163.0,161.9$, $135.9,129.1,128.6,128.1,126.2,114.5,113.9,91.5,66.1,62.8,55.5,18.3$

Synthesis of MDBM-containing copolymer. Under a nitrogen atmosphere, the MDBM-MA, MMA monomer and azobisisobutyronitrile were dissolved into toluene at the compositions shown in Table 1, and stirred for $30 \mathrm{~min}$ at room temperature. The resulting solution was heated to initiate the radical copolymerization reaction. The reaction temperature was maintained at $60{ }^{\circ} \mathrm{C}$, and the solution was stirred under nitrogen flow for $40 \mathrm{~h}$. The reaction mixture was then poured into methanol to precipitate out the polymer. It was thoroughly washed with methanol to yield $85-88 \%$ of MDBM-containing copolymer as a white powder.

Preparation of MDBM-containing copolymer/ $\mathrm{ZrO}_{2}-\mathrm{NC}$ composite sol and film. A typical preparation process of MDBM-containing copolymer $/ \mathrm{ZrO}_{2}-$ $\mathrm{NC}$ composite sols is as follows. First, the $\mathrm{ZrO}_{2}-\mathrm{NC}$ aqueous sol was dried using an evaporator to produce a $\mathrm{ZrO}_{2}-\mathrm{NC}$ powder. The obtained $\mathrm{ZrO}_{2}$ powder was added into 2-ethoxyethanol solution and stirred for $3 \mathrm{~h}$ at room temperature until clear, which indicates non-agglomerated $\mathrm{ZrO}_{2}-\mathrm{NCs}$ in the solution. Then the MDBM-containing copolymer was added into the $\mathrm{ZrO}_{2}-\mathrm{NC}$ solution and stirred for $24 \mathrm{~h}$ at $50{ }^{\circ} \mathrm{C}$ to obtain the MDBM-containing copolymer $/ \mathrm{ZrO}_{2}-\mathrm{NC}$ composite sol (shown in Scheme 1), which had a yellow color. This sol was placed in a polypropylene container and left in a oven at $60^{\circ} \mathrm{C}$ to evaporate the solvent. Finally, the resulting film was dried in a vacuum oven to remove all traces of the solvent.

\section{RESULTS AND DISCUSSION}

Formation of coordination complexes with $\mathrm{ZrO}_{2}-\mathrm{NCs}$

Table 1 illustrates the copolymerization behavior of MMA with MDBM-MA in a toluene solution, using a lower feed MDBM-MA molar ratio ( $<4 \mathrm{~mol} \mathrm{\%}$ ) to obtain highly fluorescent nanocomposites. As can be seen from Table 1, there was virtually no difference in the molecular weights of the MDBM-containing copolymers. The copolymer composition was determined by evaluating the ${ }^{1} \mathrm{H}-\mathrm{NMR}$ spectrum. The fractions of MDBM-MA and MMA for the resulting copolymers were in agreement with the initial feed ratio.

Transparent solutions were obtained after the $\mathrm{ZrO}_{2}$-NCs were mixed with 2-ethoxyethanol at room temperature. The particle size distribution of $\mathrm{ZrO}_{2}-\mathrm{NCs}$ in the 2-ethoxyethanol solution was $2.9 \pm 0.8 \mathrm{~nm}$, as measured by dynamic light scattering. Figure 1 compares the average particle sizes of the $\mathrm{ZrO}_{2}-\mathrm{NC}$ composite sol with MDBM-containing copolymer to those of the $\mathrm{ZrO}_{2}-\mathrm{NC}$ composite sol with poly(methyl methacrylate) (PMMA) homopolymer and 1,3-bis(4-methoxyphenyl)-1,3-propanedione. The PMMA homopolymer $\left(M_{\mathrm{n}}=17000, M_{\mathrm{w}}=30000\right)$ prepared by free radical polymerization was used to investigate the crosslinking effect of the MDBM-containing copolymer on the formation of coordination complexes with the $\mathrm{ZrO}_{2}$-NCs.

To confirm MDBM absorption, the quantities of MDBM moiety in the copolymer were varied from 3 to $20 \mathrm{U}$ per one $\mathrm{ZrO}_{2}$ nanoparticle to account for the possibility of attaching all MDBM moieties. The average particle size of the $\mathrm{ZrO}_{2}-\mathrm{NC}$ composite sol with MDBMcontaining copolymer (Figures $1 \mathrm{a}$ and $\mathrm{b}$ ) was increased, depending on the content of the charged $\mathrm{ZrO}_{2}-\mathrm{NC}$, after the addition of the $\mathrm{ZrO}_{2}$ NCs. This behavior can be explained by the formation of coordination complexes between the $\mathrm{ZrO}_{2}$-NCs and the MDBM-containing copolymers, which resulted in increased crosslinking due to additional $\mathrm{ZrO}_{2}$-NCs. Upon further increase of the $\mathrm{ZrO}_{2}-\mathrm{NC}$ content, interactions between the $\mathrm{ZrO}_{2}-\mathrm{NCs}$ and MDBM moieties should cause the

Table 1 Copolymerization of MDBM-MA and MMA $\left(60^{\circ} \mathrm{C}, 40 \mathrm{~h} \text { in } \mathrm{N}_{2}\right)^{\mathrm{a}}$

\begin{tabular}{|c|c|c|c|c|c|c|}
\hline Entry & $\mathrm{m}_{1}^{\mathrm{b}}(M D B M-M A)$ & $\mathrm{m}_{2}^{\mathrm{b}}(M M A)$ & $\mathrm{X}^{\mathrm{C}}(\mathrm{MDBM}-M A)$ & $Y^{c}(M M A)$ & $\mathrm{M}_{n}^{\mathrm{d}}\left(\times 10^{-3}\right)$ & $\mathrm{M}_{w} \mathrm{M}_{n}^{\mathrm{d}}$ \\
\hline Copolymer 1-25 & 0.038 & 0.962 & 0.038 & 0.962 & 19.6 & 2.0 \\
\hline Copolymer 1-50 & 0.020 & 0.980 & 0.020 & 0.980 & 21.6 & 2.1 \\
\hline
\end{tabular}

Abbreviations: MDBM-MA, 2-Propenoic acid, 2-methyl-,2-[4-[3-(4-methoxyphenyl)-1,3-dioxopropyl]phenoxy]ethyl ester; MMA, methyl methacrylate.

Monomer concentration: $2.0 \mathrm{~mol} \mathrm{I}^{-1}$ of toluene solution.

${ }^{\mathrm{a}} 0.01 \mathrm{~mol} \%$ of azobisisobutyronitrile as an initiator was used.

$\mathrm{b}_{1}, \mathrm{~m}_{2}$ : molar fractions of MDBM-MA and MMA in the feed.

${ }^{C} X, Y$ : molar fractions of MDBM-MA and MMA incorporated in the copolymer estimated by ${ }^{1} \mathrm{H}$ nuclear magnetic resonance.

dEstimated by size-exclusion chromatography based on polystyrene standard in tetrahydrofuran. 


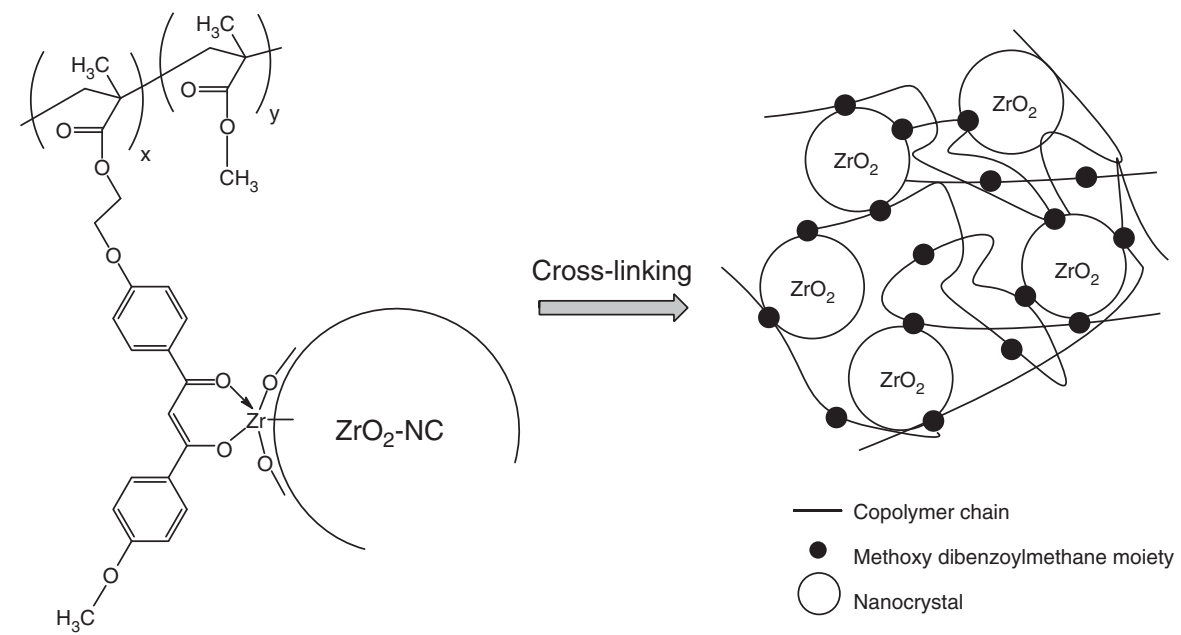

Scheme 1 Construction of the methoxy-functionalized dibenzoylmethane-containing copolymer/zirconium oxide nanocrystal composite material.

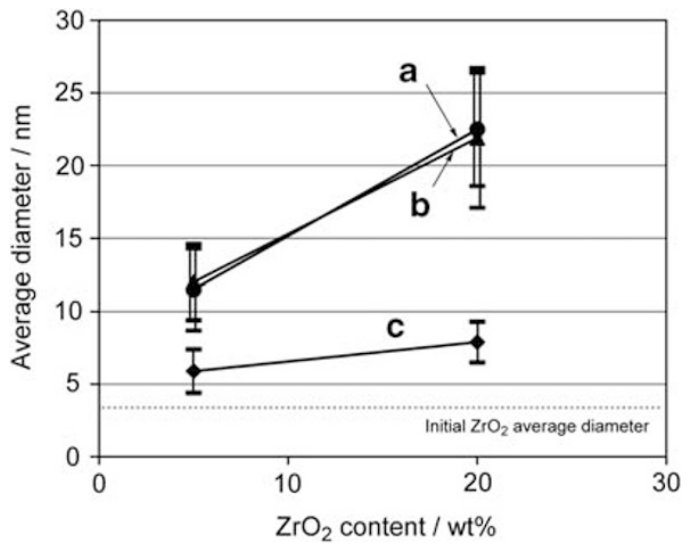

Figure 1 The average diameter of zirconium oxide nanocrystals $\left(\mathrm{ZrO}_{2}-\mathrm{NCs}\right)$ in the composite sols: (a) copolymer $1-25 / \mathrm{ZrO}_{2}-\mathrm{NC}$ composite sol, (b) copolymer $1-50 / \mathrm{ZrO}_{2}-\mathrm{NC}$ composite sol and (c) $\mathrm{ZrO}_{2}-\mathrm{NC}$ composite sol with poly(methyl methacrylate) (PMMA) and 1,3-bis(4-methoxyphenyl)-1,3propanedione. The polymer and charged $\mathrm{ZrO}_{2}-\mathrm{NC}$ were maintained at 1.3 $w t \%$ in the composite sols. The feed amount of 1,3-bis(4-methoxyphenyl)1,3- propanedione in the $\mathrm{ZrO}_{2}$ - $\mathrm{NC}$ composite sol with PMMA had the same molarity as the methoxy-functionalized dibenzoylmethane ligand of the copolymer $1-25 / \mathrm{ZrO}_{2}$-NC composite sol.

number of aggregates and the size of the composite particles to increase. However, the average particle size in the composite sol was not affected by the difference in the amount of MDBM moiety in the copolymer because of steric hindrance from the polymer chain (Figures 1a and b). The $\mathrm{ZrO}_{2}-\mathrm{NC}$ composite sol with the PMMA homopolymer (Figure 1c) had small average particle sizes that were $<10 \mathrm{~nm}$. This result clearly shows that no interaction between the $\mathrm{ZrO}_{2}$-NCs and the PMMA homopolymer took place in the composite sol.

The Fourier transform infrared spectra of the copolymer 1-25/ $\mathrm{ZrO}_{2}-\mathrm{NC}$ composite and the copolymer 1-25 (Table 1) are presented in Figure 2. The spectrum of copolymer 1-25 shows a fairly strong maximum at $3439 \mathrm{~cm}^{-1}$ (Figure $2 \mathrm{~b}$ ). This band was attributed to the presence of the enol form in the copolymer 1-25. The chelate carbonyl band in the Fourier transform infrared spectrum can be resolved into a group of bands with the first member at $1589 \mathrm{~cm}^{-1}$, with an antisymmetric stretch of chelated $\mathrm{C}=\mathrm{O}$. Another sharp and intense peak appears at $1533 \mathrm{~cm}^{-1}$, with a symmetric stretch of chelated $\mathrm{C}=\mathrm{O}$. These characteristic peaks were also observed in the composite (Figure 2a), which strongly suggests that MDBM was absorbed onto $\mathrm{ZrO}_{2}$-NC surfaces in a chelate form. However, it was found that the peaks near 1603 and $1491 \mathrm{~cm}^{-1}$ are very similar to those of $\mathrm{TiO}_{2}$ nanoparticles, where butyl methoxy dibenzoylmethane adsorbed in the enol form is present. ${ }^{16}$ In this work, these peaks are probably the result of weakly adsorbed MDBM in the enol form, but not chelated to $\mathrm{ZrO}_{2}$-NC. In fact, as shown in Figure 2a, the enol form shows a weak peak at $3439 \mathrm{~cm}^{-1}$ in the Fourier transform infrared spectra of the composite. From the ${ }^{1} \mathrm{H}-\mathrm{NMR}$ studies, the rate of chelated MDBM onto $\mathrm{ZrO}_{2}-\mathrm{NC}$ surfaces was determined as $60 \%$ by relative integration of the peak at 17.1 p.p.m., corresponding to the enol protons of the MDBM-containing copolymer. Thus, it appears that chelated MDBM and some physisorbed material are present on the $\mathrm{ZrO}_{2}$-NC surface.

Morphology of MDBM-containing copolymer/ZrO $\mathrm{Zn}_{2}-\mathrm{NC}$ composites The homogeneity of the obtained copolymer $1-25 / \mathrm{ZrO}_{2}-\mathrm{NC}$ composite was investigated by scanning electron microscopy (Figure 3). Phase separation of the $\mathrm{PMMA} / \mathrm{ZrO}_{2}-\mathrm{NC}$ composite with 1,3-bis(4-methoxyphenyl)-1,3-propanedione was observed, as shown in Figure 3b. Micrometer-sized white precipitates indicate aggregated $\mathrm{ZrO}_{2}-\mathrm{NCs}$. In contrast, $\mathrm{ZrO}_{2}$-NCs were well dispersed in the copolymer $1-25 / \mathrm{ZrO}_{2}-\mathrm{NC}$ composites, as shown in Figure $3 \mathrm{a}$. These results strongly indicate that the formation of coordination complexes between the $\mathrm{ZrO}_{2}-\mathrm{NCs}$ and the MDBM ligands has an important role for the nanometer scale miscibility for copolymer $1-25 / \mathrm{ZrO}_{2}-\mathrm{NC}$ composites.

\section{Optical properties and photostability of MDBM-containing copolymer/ $\mathrm{ZrO}_{2}-\mathrm{NC}$ composites}

The optical properties of the obtained MDBM-containing copolymer/ $\mathrm{ZrO}_{2}$-NC composites were investigated by ultraviolet-visible absorption and photoluminescence spectroscopy. The ultraviolet-visible absorption and photoluminescence spectra of the copolymer 1-50/ $\mathrm{ZrO}_{2}-\mathrm{NC}$ composites are shown in Figures 4 and 5, respectively. As can be seen in Figure $4 \mathrm{a}$, the copolymer $1-50$ has an intense absorption maximum at $362 \mathrm{~nm}$, which is attributed to the $\pi-\pi^{*}$ transitions of the enols. ${ }^{17}$ The absorption peak at $379 \mathrm{~nm}$, which is attributed to the $\pi-\pi^{\star}$ electron transition from dibenzoylmethane, is 

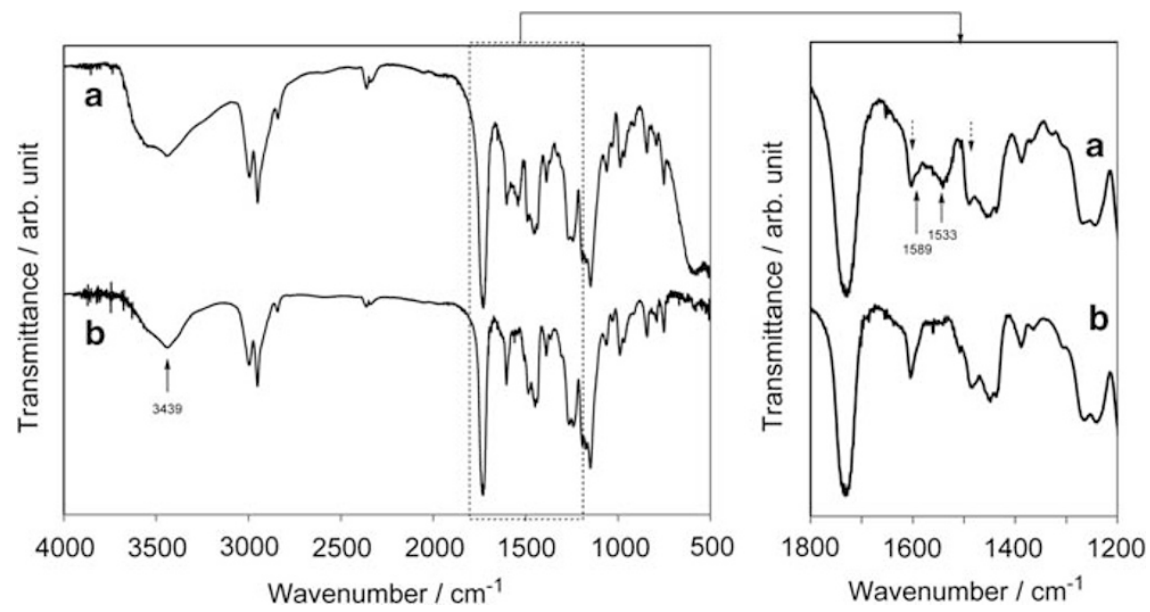

Figure 2 Fourier transform infrared spectra of (a) 80 wt\% copolymer 1-25/20 wt\% zirconium oxide nanocrystal composite and (b) copolymer 1-25.
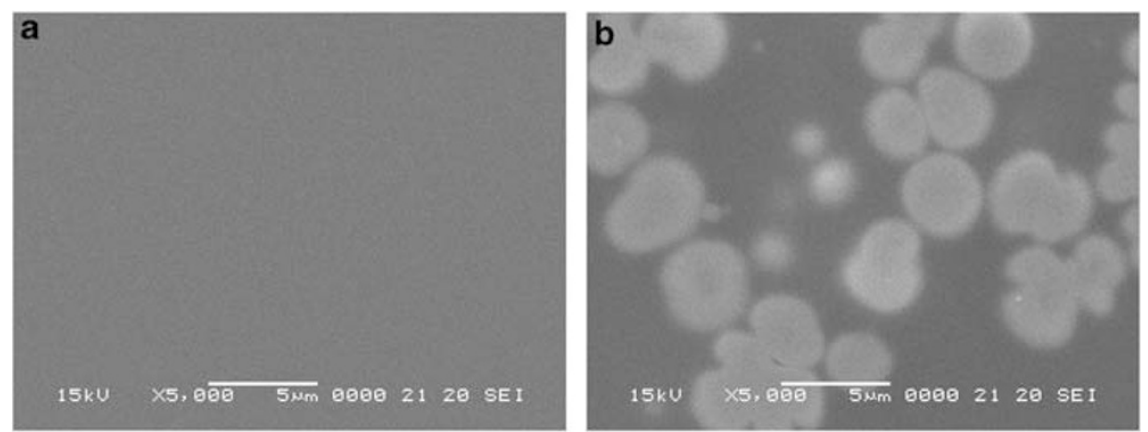

Figure 3 Scanning electron microscopy images of (a) 80 wt\% copolymer 1-25/20 wt\% zirconium oxide nanocrystal ( $\mathrm{ZrO}_{2}-\mathrm{NC}$ ) composite and (b) 80 wt\% poly(methyl methacrylate)/20 wt\% $\mathrm{ZrO}_{2}$-NC composite with 1,3-bis(4-methoxyphenyl)-1,3-propanedione. The 1,3-bis(4-methoxyphenyl)-1,3-propanedione feed ratio had the same molarity as the methoxy-functionalized dibenzoylmethane -containing copolymer/ZrO ${ }_{2}-\mathrm{NC}$ composite.

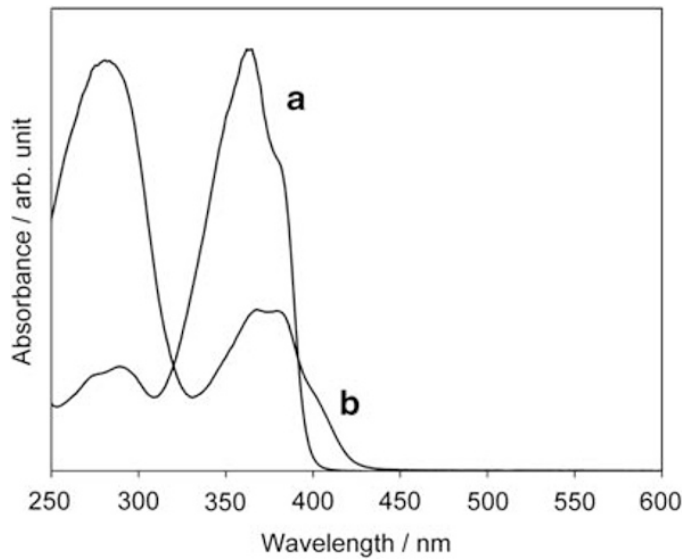

Figure 4 Ultraviolet-visible spectra of (a) copolymer 1-50 and (b) 80 wt\% copolymer $1-50 / 20$ wt\% zirconium oxide nanocrystal composite in 2ethoxyethanol.

slightly red-shifted for the copolymer $1-50 / \mathrm{ZrO}_{2}-\mathrm{NC}$ composite from that of the copolymer 1-50. Furthermore, the spectra for the co polymer $1-50 / \mathrm{ZrO}_{2}-\mathrm{NC}$ composite show that the new shoulder peak $\sim 410 \mathrm{~nm}$, which arises from the zirconium 1,3-diketonate complex, is similar to the absorption maximum of boron 1,3-diketonate dyes from the design of diarylboron complexes. ${ }^{18}$ According to these

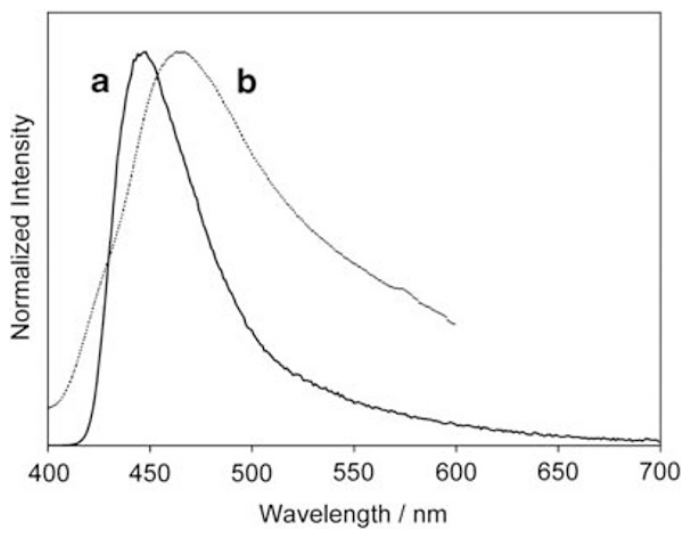

Figure 5 Normalized fluorescent spectra of (a) 80 wt\% copolymer 1-50/20 wt\% zirconium oxide nanocrystal $\left(\mathrm{ZrO}_{2}-\mathrm{NC}\right)$ composite in 2-ethoxyethanol and (b) $80 \mathrm{wt} \%$ copolymer 1-50/20 wt\% $\mathrm{ZrO}_{2}-\mathrm{NC}$ composite film excited at $379 \mathrm{~nm}$.

results, the MDBM moieties were absorbed onto $\mathrm{ZrO}_{2}-\mathrm{NC}$ surfaces and formed coordination complexes with $\mathrm{ZrO}_{2}-\mathrm{NCs}$.

The photoluminescence spectra for the 2-ethoxyethanol, copolymer $1-50 / \mathrm{ZrO}_{2}-\mathrm{NC}$ composite show an emission maximum at $448 \mathrm{~nm}$ (Figure 5a). However, the spectra for the copolymer $1-50 / \mathrm{ZrO}_{2}-\mathrm{NC}$ composite in its solid state show a red-shifted emission peak at 

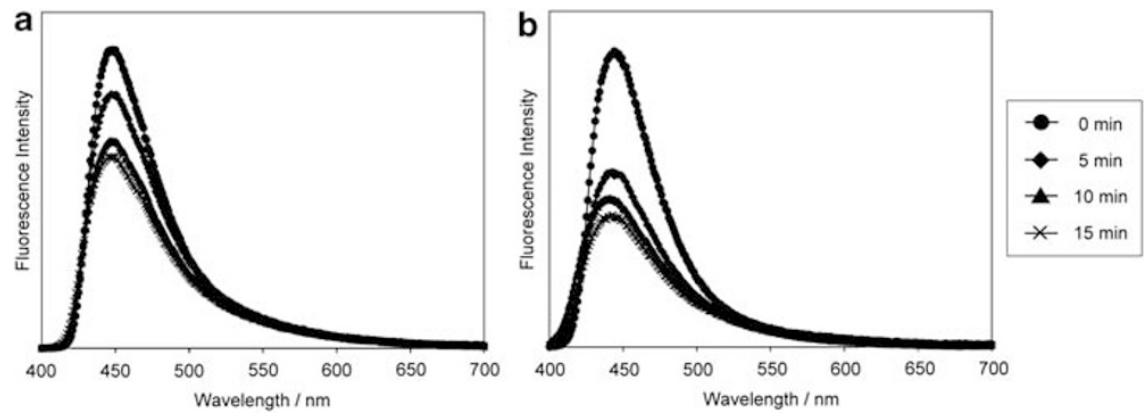

Figure 6 Influence of irradiation time on the fluorescence spectra of (a) $80 \mathrm{wt} \%$ copolymer $1-25 / 20 \mathrm{wt} \%$ zirconium oxide nanocrystal ( $\mathrm{ZrO}_{2}-\mathrm{NC}_{\text {) }}$ composite and (b) $80 \mathrm{wt} \%$ poly(methyl methacrylate)/20 wt\% $\mathrm{ZrO}_{2}-\mathrm{NC}$ composite with 1,3-bis(4-methoxyphenyl)-1,3-propanedione in 2-ethoxyethanol. The methoxyfunctionalized dibenzoylmethane moiety concentration was fixed at $3.2 \times 10^{-3} \mathrm{M}$ in the composite sol.
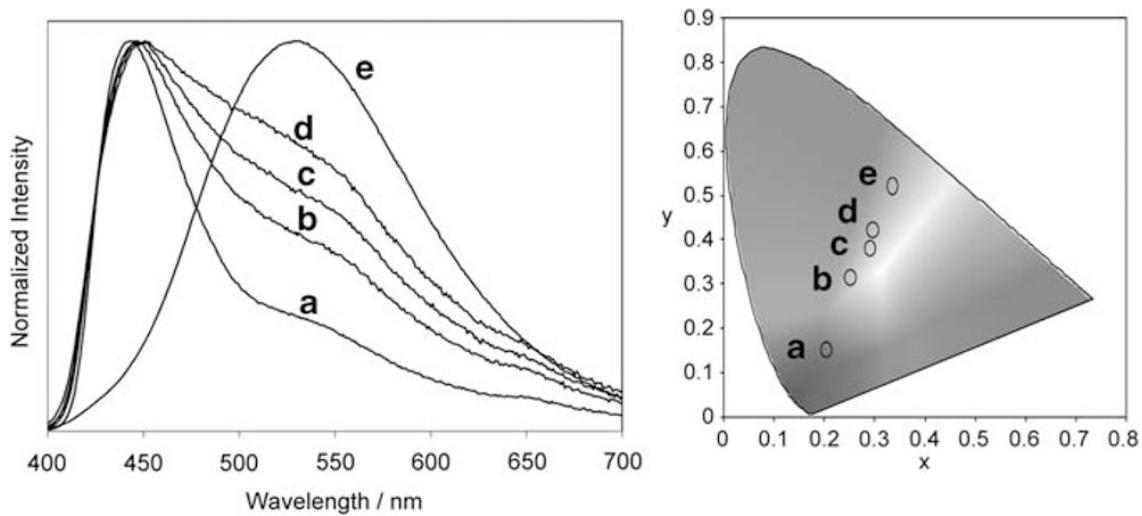

Figure 7 Fluorescence spectra and Commission Internationale de L'Eclairage $1931(x, y)$ chromaticity diagram of 8-quinolinol-containing copolymer 1-50/ methoxy-functionalized dibenzoylmethane-containing copolymer 1-50/zirconium oxide nanocrystal $\left(\mathrm{ZrO}_{2}-\mathrm{NC}\right)$ composites with the weight ratios of (a) $0 / 80 /$ 20 , (b) $27 / 53 / 20$, (c) $40 / 40 / 20$, (d) $53 / 27 / 20$ and (e) $80 / 0 / 20$. The ligand concentration was fixed at $1.6 \times 10^{-3} \mathrm{M}$ in 2 -ethoxyethanol solution. The fluorescent spectra were normalized, and the binary blends, which were excited at $379 \mathrm{~nm}$, were prepared by adding various amounts of ligand-containing copolymer/ZrO $2-\mathrm{NC}$ composite sols.

$463 \mathrm{~nm}$. This red shift could be due to an efficient $\pi$-stacking of the plane molecules of the MDBM.

Photostability of the MDBM-containing copolymer/ $\mathrm{ZrO}_{2}-\mathrm{NC}$ composite was investigated by UV irradiation experiments. Improvement of emission properties and stability of the composite were expected due to the limited ligand mobility on $\mathrm{ZrO}_{2}$-NCs. To identify the durability of chemical bonding between organic and inorganic components, $\mathrm{ZrO}_{2}-\mathrm{NC}$ composites with PMMA and 1,3-bis(4-methoxyphenyl)-1,3-propanedione were also prepared. Solutions of 2-ethoxyethanol with composites (with concentration $3.2 \times 10^{-3} \mathrm{M}$ as an MDBM ligand) in a quartz cell were irradiated by UV light under aerobic conditions, and their photodecomposition was traced by measuring their fluorescence spectra. Figure 6 shows the time dependence of the fluorescence spectra of the composites under UV irradiation. After $15 \mathrm{~min}$ of UV irradiation, the fluorescence of the $\mathrm{PMMA} / \mathrm{ZrO}_{2}$-NC composite with 1,3-bis-(4-methoxyphenyl)-1,3propanedione was slightly blue-shifted, and the fluorescence intensity was quenched below 45\% (Figure 6b). This shift was attributed to weak fluorescence from $\mathrm{ZrO}_{2}$-NCs. The fluorescence intensity of the copolymer $1-25 / \mathrm{ZrO}_{2}-\mathrm{NC}$ composite solution shows a small decrease $(<36 \%)$ after UV irradiation for $15 \mathrm{~min}$ (Figure 6a). The reduction in the spectra intensity with UV irradiation tended to be deterred by the addition of copolymer $1-25$ to the $\mathrm{ZrO}_{2}-\mathrm{NC}$. The degradation mechanism of the composite by UV light was unclear, but oxygen and water in the air should have harmful effects on ligand decomposition, especially for composites without ligand protection from the polymer chain. This conclusion was supported by the degradation in fluorescence of the $\mathrm{PMMA} / \mathrm{ZrO}_{2}-\mathrm{NC}$ composite with 1,3-bis(4-methoxyphenyl)-1,3-propanedione (Figure 6b). The bulky nature of the $\mathrm{ZrO}_{2}-\mathrm{NC}$ and adsorption of MDBM in the copolymer resulted in fluorescence stability and durability for the composites. The ligand immobilized by the organic/inorganic sandwich structure is crucial for obtaining highly stabilized luminescent nanocomposites.

\section{Emission color tuning}

The blue emission from the composite can be tuned by the addition of 8-hydroxyquinoline-containing copolymer in the copolymer 1-50/ $\mathrm{ZrO}_{2}$-NC composite, which emits a yellow-green color from the zirconium quinolate bonded onto the $\mathrm{ZrO}_{2}-\mathrm{NC} .{ }^{10}$ Even though the simple blending of fluorophores is an important technology for emission color tuning (especially for white emission), the precise control of the emission spectrum in multi-component systems needs to be studied further because of Förster resonance energy transfer among the components. ${ }^{19,20}$ In this non-radiative energy transfer mechanism, a photoexcited donor fluorophore transfers its energy to an acceptor fluorophore of a different species within a minimum distance (Förster radius) after absorption of a higher energy photon. The occurrence of Förster resonance energy transfer is made evident by a decrease in donor photoemission accompanied by an increase in acceptor fluorescence. However, as can be seen in Figure 7, blue emission from the zirconium 1,3-diketonate complex on $\mathrm{ZrO}_{2}-\mathrm{NC}$ is retained even with an increase in the amount of 
8-hydroxyquinoline-containing copolymer. It seems that energy transfer from the MDBM moiety to the 8-quinolinol moiety rarely takes place in the composite sols, despite high ligand concentration $\left(\sim 10^{-3} \mathrm{M}\right)$. This result clearly shows that the ligands in the copolymer are separated from each other by a steric hindrance from $\mathrm{ZrO}_{2}-\mathrm{NC}$ and copolymer chain, and ligand immobilization between organic and inorganic components is extremely useful in preventing the energy transfer.

The Commission Internationale de L'Eclairage $1931(x, y)$ chromaticity diagram is also shown in Figure 7 . The obtained polymer composites show photoluminescence from blue to yellow-green with the Commission Internationale de L'Eclairage coordinates of $(0.2024$, $0.1531),(0.2531,0.3161),(0.2894,0.3814),(0.2970,0.4234)$ and $(0.3341,0.5188)$, respectively. The emission colors of the ligandcontaining copolymer $/ \mathrm{ZrO}_{2}-\mathrm{NC}$ composites were well tuned by the use of different ligands fixed between inorganic NCs and polymer chains. We propose that this design is important in controlling the emission color for white-emitting polymer nanocomposites.

\section{CONCLUSIONS}

Blue-emitting polymer nanocomposites were prepared from 1,3diketone-containing copolymers and $\mathrm{ZrO}_{2}-\mathrm{NCs}$ by forming coordination complexes with the $\mathrm{ZrO}_{2}-\mathrm{NCs}$. The $\mathrm{ZrO}_{2}-\mathrm{NCs}$ were well dispersed in the polymer matrix, with crosslinking observed on the NC surfaces. The MDBM-containing copolymer $/ \mathrm{ZrO}_{2}-\mathrm{NC}$ composites had high photostability and durability compared to the PMMA/1,3bis(4-methoxyphenyl)-1,3-propanedione/ $\mathrm{ZrO}_{2}-\mathrm{NC}$ composite without chemical bonding between the organic and inorganic components. The MDBM moieties immobilized between organic and inorganic components mimicked a sandwich-like structure, which was suitable for highly stabilized luminescent polymer nanocomposites. The blue emission from zirconium 1,3-diketonate complexes could be tuned by the addition of 8-hydroxyquinoline-containing copolymer $/ \mathrm{ZrO}_{2}-\mathrm{NC}$ composite, and its emission could be controlled from blue to yellow and finally to green as a function of the blend composition. This material design, in which the ligand would be immobilized by an organic/inorganic sandwich structure, is also suitable for optoelectronic materials with controlled emission color.
1 Novak, B. M. Hybrid nanocomposite materials - between inorganic glasses and organic polymers. Adv. Mater. 5, 422-433 (1993).

2 Stein, A., Melde, B. J. \& Schroden, R. C. Hybrid inorganic-organic mesoporous silicates-nanoscopic reactors coming of age. Adv. Mater. 12, 1403-1419 (2000).

3 Sanchez, C. \& Ribot, F. Design of hybrid organic-inorganic materials synthesized via sol-gel chemistry. New J. Chem. 18, 1007-1047 (1994).

4 Okada, A. \& Usuki, A. The chemistry of polymer-clay hybrids. Mater. Sci. Eng. C 3 , 109-115 (1995)

5 Mark, J. E. Ceramic-reinforced polymers and polymer-modified ceramics. Polym. Eng. Sci. 36, 2905-2920 (1996).

6 Giraudeau, A., Fan, F.- R. F. \& Bard, A. J. Semiconductor electrodes. 30. Spectral sensitization of the semiconductors $\mathrm{n}-\mathrm{TiO}_{2}$ and $\mathrm{n}-\mathrm{WO}_{3}$ with metal phthalocyanines. J. Am. Chem. Soc. 102, 5137-5142 (1980).

7 Ghosh, P. K. \& Spiro, T. G. Photoelectrochemistry of tris(bipyridyl)ruthenium(II) covalently attached to n-type $\mathrm{SnO}_{2}$. J. Am. Chem. Soc. 102, 5543-5549 (1980).

8 Borgarello, E., Kiwi, J., Pelizzetti, E., Visca, M. \& Gratzel, M. Photochemical cleavage of water by photocatalysis. Nature 279, 158-160 (1981).

9 Houlding, V. H. \& Gratzel, M. Photochemical $\mathrm{H}_{2}$ generation by visible light. Sensitization of $\mathrm{TiO}_{2}$ particles by surface complexation with 8-hydroxyquinoline. J. Am. Chem. Soc. 105, 5695-5696 (1983).

10 Otsuka, T. \& Chujo, Y. Highly stabilized luminescent polymer nanocomposites: fluorescence emission from metal quinolate complexes with inorganic nanocrystals. J. Mater. Chem. 20, 10688-10695 (2010).

11 Otsuka, T. \& Chujo, Y. Preparation and characterization of poly(vinylpyrrolidone)/ zirconium oxide hybrids by using inorganic nanocrystals. Polym. J. 40, 1157-1163 (2008).

12 Otsuka, T. \& Chujo, Y. Synthesis of transparent poly(vinylidene fluoride) (PVdF)/zirconium oxide hybrids without crystallization of PVdF chains. Polymer 50, 3174-3181 (2009)

13 Otsuka, T. \& Chujo, Y. Poly(methyl methacrylate) (PMMA)-based hybrid materials with reactive zirconium oxide nanocrystals. Polym. J. 42, 58-65 (2010).

14 Fukuoka, N., Yasuda, H., Nishimatsu, M. Mitsuta, M. \& Omae, Y. Polymer of dibenzoylmethane-based derivative, copolymer composed of the dibenzoylmethanebased derivative and polymerizable monomer, method for producing the same and use thereof. JP Patent 2003-082026 (2003).

15 Bender, J. L., Shen, Q.- D. \& Fraser, C. L. Poly( $\varepsilon$-caprolactone) macroligands with $\beta$-diketonate binding sites: synthesis and coordination chemistry. Tetrahedron 60 , 7277-7285 (2004).

16 Egerton, T. A., Everall, N. J., Mattinson, J. A., Kessell, L. M. \& Tooley, I. R. Interaction of $\mathrm{TiO}_{2}$ nano-particles with organic UV absorbers. J. Photochem. Photobio. A: Chem. 193, 10-17 (2008).

17 Hammond, G. S., Borduin, W. G. \& Guter, G. A. Chelates of $\beta$-diketones. 2. Enolization, ionization and spectra. J. Am. Chem. Soc. 81, 4682-4686 (1959).

18 Nagai, A., Kokado, K., Nagata, Y., Arita, M. \& Chujo, Y. Highly intense fluorescent diarylboron diketonate. J. Org. Chem. 73, 8605-8607 (2008).

19 Förster, T. 10th Spiers memorial lecture. Transfer mechanisms of electronic excitation. Diss. Faraday Soc. 27, 7-17 (1959).

20 Hillisch, A., Lorenz, M. \& Diekmann, S. Recent advances in FRET: distance determination in protein-DNA complexes. Curr. Opin. Struct. Biol. 11, 201-207 (2001). 